\title{
Standard Surgical Skin Markers Should Be Avoided for Intraoperative Vein Graft Marking during Cardiac and Peripheral Bypass Operations
}

\author{
Eric S. Wise ${ }^{1 *}$, Joyce Cheung-Flynn ${ }^{1}$ and Colleen Marie Brophy ${ }^{1,2}$ \\ 'Department of Surgery, Vanderbilt University, Nashville, TN, USA, ${ }^{2}$ VA Tennessee Valley Healthcare System, Vanderbilt \\ University, Nashville, TN, USA
}

Keywords: coronary artery bypass, vein graft disease, saphenous vein, surgical skin markers, brilliant blue FCF

OPEN ACCESS

Edited by:

Faisal Aziz,

Penn State Hershey College of

Medicine, USA

Reviewed by:

John Frank Radtka,

Penn State Hershey Medical Center,

USA

Barbara Rantner,

Medical University Innsbruck, Austria

${ }^{*}$ Correspondence:

Eric S. Wise

eric.s.wise@vanderbilt.edu

Specialty section:

This article was submitted

to Vascular Surgery,

a section of the journal

Frontiers in Surgery

Received: 12 April 2016 Accepted: 06 June 2016

Published: 20 June 2016

Citation:

Wise ES, Cheung-Flynn J and Brophy CM (2016) Standard Surgical Skin Markers Should Be Avoided for

Intraoperative Vein Graft Marking

during Cardiac and Peripheral

Bypass Operations.

Front. Surg. 3:36.

doi: 10.3389/fsurg.2016.00036

\section{INTRODUCTION}

One cause of early graft failure following coronary and peripheral vein grafting is kinking or mechanical twisting of the conduit. The blind tunneling necessitated in peripheral bypasses can lead to this consequence (1). In coronary artery bypass grafting (CABG), grafts to the posterior branches of the right or circumflex coronary arteries are placed to the back of the heart and are generally the longest aortocoronary grafts. These grafts are particularly prone to twisting and kinking. Additionally, single vein grafts to two or more coronary branches ("sequential vein grafts") present special challenges with respect to maintenance of proper alignment $(2,3)$. The coronary vein graft failure rate at 1 year in the PRoject of Ex vivo Vein graft ENgineering via Transfection IV (PREVENT IV) cohort was $25 \%$, suggesting that early graft failure is a significant problem $(4,5)$. The incidence of vein graft failure due to twisting or kinking is not well studied, though some reports estimate that obstructing lesions, including but not limited to twisting or kinking, account for $15-25 \%$ of early $(<1$ year) graft failures (6-8).

Preparation and preservation techniques have advanced the field of solid organ allotransplantation, but vein graft failure rates suggest room for improvement in the handling of saphenous vein (SV) harvested for autotransplantation. Interventions for ex vivo graft treatment, including appropriate choice of preservation solution and minimization of manual pressure distension via chemical vasodilators such as papaverine, have been proposed (9-12). Additionally, the "no-touch" technique has emerged as a method of minimizing detrimental handling of graft during harvest with adventitial preservation $(4,13-15)$.

Marking of the SV graft using a surgical skin marker in an "off-label" fashion represents another such preparation technique and is the most commonly employed method of preventing graft torsion (16). This marking allows for the maintenance of continuous alignment along the length of the vein in the same longitudinal plane. These lines provide a visible guide for surgeons to use during conduit routing and tunneling to avoid mechanical obstructions related to vein alignment (17). While operating rooms have adapted less traumatic methods of vein harvest, preservation, and distension, surgical skin marker use remains ubiquitous as the primary method to maintain graft orientation. The use of surgical skin markers during graft preparation is toxic to the tissue and impairs physiologic function (16). We argue that the data support avoidance of standard surgical skin markers for marking on vascular tissue; We further contend that brilliant blue FCF (for coloring food) may represent a viable alternative dye for intraoperative graft marking. 


\section{CURRENT STATUS OF GRAFT MARKING}

Also known as crystal violet, gentian violet has emerged as the most common dye used in surgical skin marking in the United States, replacing methylene blue in the mid-1990s (18). Most commercially available markers approved for use to mark skin contain $10 \%$ gentian violet dye in an isopropyl alcohol solvent, at up to $50 \%$ by weight (16). In addition to off-label use on vein grafts, gentian violet-based surgical skin markers are routinely used to mark other human tissue intraoperatively, including tendon and eye tissue such as donor cornea and anterior lens capsule (19-22). Influence of the gentian violet marker on residual human hamstring tendon following graft placement during anterior cruciate ligament reconstruction was assessed using an in vitro live-dead assay. The study found that marking caused pronounced cell death and inhibited tenocyte migration, representing a total failure of explant vigor (20). While the effect on clinical outcome has not yet been realized, the authors recommended minimization of tendon marking. In ocular tissue, gentian violet pen markings are often made on a microscale on transplanted corneal tissue to maintain orientation and to anterior lens capsular tissue to facilitate intraoperative visualization in cataract surgery $(19,22)$. To this effect, there is evidence that suggests the dye may be toxic to donor corneal endothelium in Descemet-stripping automated endothelial keratoplasty and to anterior lens epithelial cells in corneal surgery.

Few studies have addressed the mechanism by which gentian violet affects mammalian cells, at the molecular level. On the one hand, gentian violet blocks the activity of nicotinamide adenine dinucleotide phosphate oxidases, avoiding the generation of superoxide radicals and subsequent inflammation (23). However, gentian violet also has been shown to bind to intracellular deoxyribonucleic acid, precluding DNA replication and excision repair (24).

The effect of gentian violet on human vessels is controversial. It was previously reported that when applied to human venous tissue, gentian violet acutely preserved physiologic functional responses better than methylene blue, as measured on an organ bath $(16,18)$. More specifically, these studies showed that topical gentian violet application did not significantly impair smooth muscle contractile strength induced by potassium chloride and phenylephrine stimuli or vasodilatory response to cholinergics and calcium channel blockers; dilatory responses to sodium nitroprusside, however, were significantly decreased (18). During the course of physiologic studies using human SV surgical remnants from CABG patients, our laboratory observed that tissue segments with signs of surgical skin marker containing both gentian violet and isopropyl alcohol displayed markedly impaired responses in the muscle bath. Human SV samples were marked with the standard surgical skin markers and, after equilibration on an organ bath, were challenged with vasoactive agents. Compared with unmarked control segments, the marked segments demonstrated impaired contractility in response to potassium chloride and phenylephrine agonists and decreased endothelial-dependent relaxation in response to carbachol, a cholinomimetic (16). The cytotoxic effects of topical gentian violet dye on cultured human umbilical venous smooth muscle cells has recently been reported. Brief exposure of these cells to topical gentian violet dye at subclinical concentrations leads to cytologic fixation. Additionally, this treatment leads to enhanced dead cell protease release relative to control cells, as determined via the CytoTox-Glo assay (25).

Isopropyl alcohol is a clear, colorless liquid with many commercial applications, including cosmetics, antifreezes, and cleaners. It is the solvent used for gentian violet in current surgical skin markers. Topical application of isopropyl alcohol on a vessel carries the risk of systemic absorption, although subsequent hepatic conversion to acetone via alcohol dehydrogenase may reduce the harm. Unlike other alcohols, isopropyl alcohol itself, rather than its product of oxidation, is responsible for the toxic effects $(26,27)$.

The physiologic effect of isopropyl alcohol on human SV was also investigated in our laboratory and reported in 2011 (16). As seen with standard surgical skin marking, contractile responses of human SV rings in response to potassium chloride and phenylephrine challenge were decreased in tissues briefly preserved in 50\% aqueous isopropyl alcohol, when assessed on an organ bath (16). Endothelial-dependent relaxation was also impaired with isopropyl alcohol-preserved tissues. Diminished contractile responses to potassium chloride have been associated with decreased viability of human SV. Evidence of isopropyl alcoholinduced cellular damage has been further supported by staining with trypan blue, a vital stain used to detect dead tissue. Cultured human umbilical venous smooth muscle cells, after a 15-min exposure to $50 \%$ isopropyl alcohol, histologically demonstrated significantly increased uptake of trypan blue. Additionally, isopropyl alcohol exposure, as seen with gentian violet, led to an increase in cytotoxicity as determined via the CytoTox-Glo assay (25). Most concerning, this pattern of acute cellular injury to the conduit may portend a poor graft performance, leading to thrombosis and acceleration of neointimal hyperplasia (28-30).

\section{PROPOSED ALTERNATIVE}

A common food colorant, FCF is a triarylmethane water-soluble dye that is found to be safe in commonly ingested doses (31). Topically, FCF appears as a distinct bright blue similar to methylene blue and, like current vein graft dyes, is easily distinguishable in the intraoperative setting from blood, irrigants, and surrounding muscle and connective tissue (Figure 1). As a structural analog of brilliant blue G, it was plausible that FCF too may inhibit P2X, receptors, cell surface receptors whose activation is induced by the trauma of intraoperative graft manipulation. Our laboratory has shown that these receptors are implicated in proliferation, migration, and apoptosis of vascular smooth muscle cells (32). Due to its established safety profile and potential for amelioration of preparation-induced conduit injury via $\mathrm{P}_{2} \mathrm{X}_{7}$ receptor inhibition, FCF represented a practical candidate for a substitute vein graft dye $(25,32)$.

Evidence of FCF-governed $\mathrm{P}_{2} \mathrm{X}_{7}$ inhibition has been reported, primarily from our laboratory. The $\mathrm{P}_{2} \mathrm{X}_{7}$ agonist, $2^{\prime}\left(3^{\prime}\right)-\mathrm{O}-(4-$ benzoylbenzoyl)adenosine- $5^{\prime}$-triphosphate (BzATP), was added to an organ bath containing suspended unprepared human SV rings left as untreated control or pretreated with a topical FCF. 

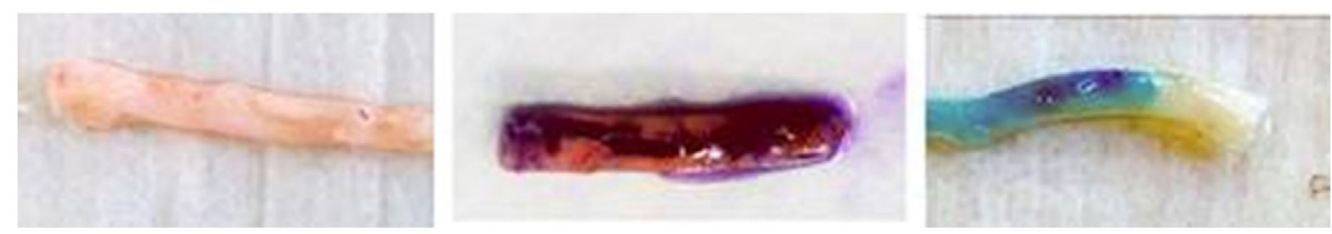

FIGURE 1 | Ink markings on human saphenous vein graft. Left - unmarked human saphenous vein; Middle - human saphenous vein marked with a standard surgical skin marker (gentian violet dye and isopropyl alcohol solvent); Right - human saphenous vein marked with brilliant blue FCF-based marking pen (FCF dye and glycerol solvent).

The FCF-treated rings demonstrated reduced BzATP-induced, $\mathrm{P}_{2} \mathrm{X}_{7}$-governed contractile responses, suggesting that $\mathrm{P} 2 \mathrm{X}_{7}$ receptors were inhibited (32). $\mathrm{P} 2 \mathrm{X}_{7}$ receptor activation leads to increases in intracellular calcium concentrations (33). Further evidence supporting the proposed mechanism of action of FCF was recently reported, as FCF pretreatment of rat aorta prevented intracellular calcium flux governed by BzATP-induced $\mathrm{P}_{2} \mathrm{X}_{7}$ activation, as detected by a FluoroPlex apparatus (25).

We have also examined the topical effect of FCF on vascular conduit. Human SV samples were obtained from CABG patients prior to preparation or preservation, and baseline physiologic responses were determined in an organ bath (32). The decrement in endothelial-dependent relaxation observed after $2 \mathrm{~h}$ of preservation in heparinized Plasma-Lyte A was mitigated by the addition of aqueous FCF to the preservation solution (32). Moreover, in some human SV samples that were initially unresponsive to a depolarizing $\mathrm{KCl}$ stimulus, FCF restored smooth muscle contractility and hence, functional viability (32). Exposure of cultured human umbilical venous smooth muscle cells to clinically applicable doses of topical FCF has recently been shown to lead to neither increased trypan blue staining relative to control nor increased dead cell protease release via the CytoTox-Glo assay, in contrast to the effects observed with topical gentian violet and isopropyl alcohol (25).

In addition to its effects on acute physiologic responses and cellular viability of vascular tissue, we have also reported the influence of FCF treatment on intimal hyperplasia (32). Unmanipulated human SV rings were treated for $2 \mathrm{~h}$ in solution with and without FCF, and maintained in organ culture over 14 days. While a significant increase in intimal thickness was noted among untreated veins, this was mitigated in the

\section{REFERENCES}

1. Eifell R, Mudawi A. A simple technique to prevent graft kinking during tunneling of a reversed vein femoropopliteal bypass graft. Surg Today (2007) 37:356-8. doi:10.1007/s00595-006-3337-z

2. Kim HJ, Lee TY, Kim JB, Cho WC, Jung SH, Chung $\mathrm{CH}$, et al. The impact of sequential versus single anastomoses on flow characteristics and mid-term patency of saphenous vein grafts in coronary bypass grafting. J Thorac Cardiovasc Surg (2011) 141:750-4. doi:10.1016/j. jtcvs.2010.05.037

3. Li J, Liu Y, Zheng J, Bai T, Liu Y, Wang X, et al. The patency of sequential and individual vein coronary bypass grafts: a systematic review. Ann Thorac Surg (2011) 92:1292-8. doi:10.1016/j.athoracsur.2011.05.038
FCF-treated vein group (32). FCF, as a topical vein graft treatment in a rabbit external jugular-carotid artery interposition model, led to reduced neointimal growth relative to control grafts (34). Finally, platelet-derived growth factor-induced migration and proliferation were examined in A7r5 smooth muscle cells. FCF pretreatment abrogated both cellular migration and proliferation (34).

\section{CONCLUSION}

The "off-label" use of surgical skin markers have been shown to impair physiologic responses in human SV graft and to be cytotoxic. Surgeons should consider minimizing or eliminating the off-label use of surgical skin markers for vein marking. FCF is a plausible alternative dye for graft marking in that it preserves endothelial and smooth muscle function and inhibits neointimal growth in human SV. Moreover, FCF is also the only dye that is currently approved by the FDA for use in marking human SV.

\section{AUTHOR CONTRIBUTIONS}

EW contributed to research and writing of the manuscript. JC-F contributed to research and critical revision of the manuscript. $\mathrm{CB}$ oversaw all respects of the research and composition of the manuscript. All authors gave final approval.

\section{FUNDING}

There were no relevant sources of funding applicable to this manuscript.

4. Alexander JH, Ferguson TB Jr, Joseph DM, Mack MJ, Wolf RK, Gibson CM, et al. The project of ex-vivo vein graft engineering via transfection IV (PREVENT IV) trial: study rationale, design, and baseline patient characteristics. Am Heart J (2005) 150:643-9. doi:10.1016/j.ahj.2005. 05.021

5. Lopes RD, Williams JB, Mehta RH, Reyes EM, Hafley GE, Allen KB, et al. Edifoligide and long-term outcomes after coronary artery bypass grafting: project of ex-vivo vein graft engineering via transfection IV (PREVENT IV) 5-year results. Am Heart J (2012) 164(379-386):e371. doi:10.1016/j. ahj.2012.05.019

6. Stept LL, Flinn WR, Mccarthy WJ III, Bartlett ST, Bergan JJ, Yao JS. Technical defects as a cause of early graft failure after femorodistal bypass. Arch Surg (1987) 122:599-604. doi:10.1001/archsurg.1987.01400170105015 
7. Walsh DB, Zwolak RM, Mcdaniel MD, Schneider JR, Cronenwett JL. Intragraft drug infusion as an adjunct to balloon catheter thrombectomy for salvage of thrombosed infragenicular vein grafts: a preliminary report. J Vasc Surg (1990) 11:753-9; [discussion 760]. doi:10.1067/mva.1990.19433

8. Ramanathan AK, Kwok TM. A simple technique to prevent torsion and other obstructions of autogenous vein conduits. Ann Vasc Surg (2014) 28(8):1959-60. doi:10.1016/j.avsg.2014.06.061

9. Chester AH, O'Neil GS, Tadjakarimi S, Borland JA, Yacoub MH. Effect of peri-operative storage solution on the vascular reactivity of the human saphenous vein. Eur J Cardiothorac Surg (1993) 7:399-404. doi:10.1016/1010-7940(93)90002-S

10. Chester AH, Buttery LD, Borland JA, Springall DR, Rothery S, Severs NJ, et al. Structural, biochemical and functional effects of distending pressure in the human saphenous vein: implications for bypass grafting. Coron Artery Dis (1998) 9:143-51. doi:10.1097/00019501-199809020-00012

11. Chung AW, Wong J, Luo H, Hsiang YN, Van Breemen C, Okon EB. Arterialization of a vein graft promotes cell cycle progression through Akt and p38 mitogen-activated protein kinase pathways: impact of the preparation procedure. Can J Cardiol (2007) 23:1147-54. doi:10.1016/ S0828-282X(07)70886-3

12. Tsakok M, Montgomery-Taylor S, Tsakok T. Storage of saphenous vein grafts prior to coronary artery bypass grafting: is autologous whole blood more effective than saline in preserving graft function? Interact Cardiovasc Thorac Surg (2012) 15:720-5. doi:10.1093/icvts/ivs275

13. Sepehripour AH, Jarral OA, Shipolini AR, Mccormack DJ. Does a 'no-touch' technique result in better vein patency? Interact Cardiovasc Thorac Surg (2011) 13:626-30. doi:10.1510/icvts.2011.281998

14. Sen O, Gonca S, Solakoglu S, Dalcik H, Dalcik C, Ozkara A. Comparison of conventional and no-touch techniques in harvesting saphenous vein for coronary artery bypass grafting in view of endothelial damage. Heart Surg Forum (2013) 16:E177-83. doi:10.1532/HSF98.20131006

15. Mannion JD, Marelli D, Brandt T, Stallings M, Cirks J, Dreifaldt M, et al. "No-touch" versus "endo" vein harvest: early patency on symptom-directed catheterization and harvest site complications. Innovations (Phila) (2014) 9:306-11. doi:10.1097/IMI.0000000000000084

16. Eagle S, Brophy CM, Komalavilas P, Hocking K, Putumbaka G, Osgood M, et al. Surgical skin markers impair human saphenous vein graft smooth muscle and endothelial function. Am Surg (2011) 77:922-8.

17. Abel RM. Coronary vein graft marking. Ann Thorac Surg (1983) 35:688. doi:10.1016/S0003-4975(10)61088-0

18. Shoemaker K, Rubin J, Zumbro GL, Tackett R. Evans blue and gentian violet: alternatives to methylene blue as a surgical marker dye. J Thorac Cardiovasc Surg (1996) 112:542-4. doi:10.1016/S0022-5223(96)70286-6

19. Ide T, Yoo SH, Kymionis GD, Goldman JM, Perez VL, O’Brien TP. Descemetstripping automated endothelial keratoplasty: effect of anterior lamellar corneal tissue-on/-off storage condition on Descemet-stripping automated endothelial keratoplasty donor tissue. Cornea (2008) 27:754-7. doi:10.1097/ ICO.0b013e31816a6266

20. Franklin SL, Jayadev C, Poulsen R, Hulley P, Price A. An ink surgical marker pen is damaging to tendon cells. Bone Joint Res (2012) 1:36-40. doi:10.1302/2046-3758.13.2000032

21. Stoeger C, Holiman J, Davis-Boozer D, Terry MA. The endothelial safety of using a gentian violet dry-ink "S" stamp for precut corneal tissue. Cornea (2012) 31:801-3. doi:10.1097/ICO.0b013e31823f7571
22. Andjelic S, Zupancic G, Hawlina M. The effect of gentian violet on human anterior lens epithelial cells. Curr Eye Res (2014) 39(10):1020-5. doi:10.3109/02713683.2014.894077

23. Maley AM, Arbiser JL. Gentian violet: a 19th century drug re-emerges in the 21st century. Exp Dermatol (2013) 22:775-80. doi:10.1111/exd.12257

24. Docampo R, Moreno SN. The metabolism and mode of action of gentian violet. Drug Metab Rev (1990) 22:161-78. doi:10.3109/0360253900 9041083

25. Hocking KM, Luo W, Li FD, Komalavilas P, Brophy CM, Cheung-Flynn J. Brilliant blue FCF is a nontoxic dye for saphenous vein graft marking that abrogates response to injury. J Vasc Surg (2015). doi:10.1016/j.jvs.2014.12.059

26. Vujasinovic M, Kocar M, Kramer K, Bunc M, Brvar M. Poisoning with 1-propanol and 2-propanol. Hum Exp Toxicol (2007) 26:975-8. doi:10.1177/0960327107087794

27. Jammalamadaka D, Raissi S. Ethylene glycol, methanol and isopropyl alcohol intoxication. Am JMed Sci (2010) 339:276-81. doi:10.1097/ MAJ.0b013e3181c94601

28. Hocking KM, Brophy C, Rizvi SZ, Komalavilas P, Eagle S, Leacche M, et al. Detrimental effects of mechanical stretch on smooth muscle function in saphenous veins. J Vasc Surg (2011) 53:454-60. doi:10.1016/j. jvs.2010.09.010

29. Li FD, Eagle S, Brophy C, Hocking KM, Osgood M, Komalavilas P, et al. Pressure control during preparation of saphenous veins. JAMA Surg (2014) 149:655-62. doi:10.1001/jamasurg.2013.5067

30. Osgood MJ, Hocking KM, Voskresensky IV, Li FD, Komalavilas P, Cheung-Flynn J, et al. Surgical vein graft preparation promotes cellular dysfunction, oxidative stress, and intimal hyperplasia in human saphenous vein. J Vasc Surg (2014) 60:202-11. doi:10.1016/j.jvs.2013. 06.004

31. Borzelleca JF, Hallagan JB. Safety and regulatory status of food, drug, and cosmetic color additives. ACS Symp Ser (1992) 484:377-90. doi:10.1021/ bk-1992-0484.ch031

32. Voskresensky IV, Wise ES, Hocking KM, Li FD, Osgood MJ, Komalavilas P, et al. Brilliant blue FCF as an alternative dye for saphenous vein graft marking: effect on conduit function. JAMA Surg (2014) 149:1176-81. doi:10.1001/ jamasurg.2014.2029

33. Ballerini P, Rathbone MP, Di Iorio P, Renzetti A, Giuliani P, D'Alimonte I, et al. Rat astroglial $\mathrm{P} 2 \mathrm{Z}\left(\mathrm{P} 2 \mathrm{X}_{7}\right)$ receptors regulate intracellular calcium and purine release. Neuroreport (1996) 7:2533-7. doi:10.1097/00001756-199611040-00026

34. Osgood MJ, Sexton KW, Voskresensky IV, Hocking KM, Song J, Komalavilas P, et al. Use of brilliant blue FCF during vein graft preparation inhibits intimal hyperplasia. J Vasc Surg (2015).

Conflict of Interest Statement: JC-F and CB have a proprietary interest in VasoPrep Surgical, Inc. EW has no conflicts of interest to disclose.

Copyright (๑) 2016 Wise, Cheung-Flynn and Brophy. This is an open-access article distributed under the terms of the Creative Commons Attribution License (CC BY). The use, distribution or reproduction in other forums is permitted, provided the original author(s) or licensor are credited and that the original publication in this journal is cited, in accordance with accepted academic practice. No use, distribution or reproduction is permitted which does not comply with these terms. 